\title{
Effect of Ambient Oxygen Concentration on Heating Performance of Chemical Igniter used in NASA-STD-6001B/ISO-TS16697
}

\author{
By Yuya Sugamura, ${ }^{1)}$ Aki Hosogai ${ }^{2)}$ and Yuji NAKAmurA ${ }^{1)}$ \\ ${ }^{1)}$ Department of Mechanical Engineering, Toyohashi University of Technology, Toyohashi, Japan \\ 2) JEM Utilization Center Human Spaceflight Technology Directorate, JAXA, Tsukuba, Japan
}

(Received August 3rd, 2015)

\begin{abstract}
This paper experimentally examines the heating performance brought by the chemical igniter (used in NASA-STD-6001B and ISO-TS16697) exposed in various oxygen concentrations. Final goal of this study is to discuss about the reliability of the chemical igniter for such material screening test ensuring the fire safeness in space. Prescribed mixture of nitrogen and oxygen was flowed into the test chamber and the chemical igniter is burned under the heat flux gauge. Time-sequence of heat flux brought by the chemical igniter was recorded and analyzed. It is understood that time-sequence curve of heat flux is varied under various oxygen concentration, suggesting that the thermal enthalpy accumulated in the test specimen to be burned has clear dependency on the ambient oxygen concentration. Namely, thermal status of entire test specimen is strongly depended on the environmental condition to be tested, when the chemical igniter is used as the heating source due to its inherent heating properties. Importantly, when ambient gas is strongly diluted (i.e., low oxygen concentration), complete burning of the chemical igniter tends to be prohibited, accordingly, reproducibility becomes less. Under such condition, the weak but long heating is experienced. Because such slow rate of heat supply (for ignition) shall be easily dissipated, resulting that no ignition might be induced by the chemical igniter; Hence, the chemical igniter would be insufficient to be a "universal" heating source for any screening purpose. As substitute, the electric heater (wire igniter) could work effectively to cover the disadvantages of the chemical igniter as presented in this study.
\end{abstract}

Key Words: Fire Safety, Chemical Igniter, Heat Flux, Material Flammability

\section{Introduction}

Manned space mission is the one of promising future steps and the assurance of safety is inevitable to move it forward. Especially, the crisis of fire is the critical issue to be avoided with our best knowledge because all crews would face to the severe danger immediately. To prevent the cause, currently, the materials allowed to bring to International Space Station (ISS) must pass the safety criteria regulated by NASA-STD-6001B, and the corresponding screening test is called "TEST1". 1) TEST1 is based on pass/fail measure and designed to judge the fire safeness of the materials for International Space Station (ISS) environment, namely, 101 $\mathrm{kPa}, 21 \%$ of oxygen in volume. Hence, it is not convince whether the material stay as "safe" in case it is used in other atmospheric condition (e.g., Lunar or Martian environments, other space aircraft likely Orion ${ }^{2,3)}$ ) because the material flammability generally depend on the exposed condition.

In order to evaluate the material safeness under such "beyond-ISS" environment, ULOI (Upward Limiting Oxygen Index) ${ }^{4)}$ has been proposed. It is regulated in ISO-TS16697 and stands for the index to reveal the minimum oxygen concentration needed to achieve the successful upward flame spread. ULOI were calculated with the "up-and-down method" 5), similar to LOI regulated in ISO 4589-2. In general, the material with higher ULOI shows less chance to cause a fire in space environment. This sounds reasonable and clear in some sense, however, one must be wondered in terms of ignition procedure. Recall that ISO-TS16697 shall be conducted in the closed chamber and ignition is brought by the "chemical igniter" placed at the bottom of the specimen as shown in Fig. 1. By the way TEST1 uses the exactly same chemical igniter. Important fact is that the chemical igniter is applied under various oxygen concentration to obtain ULOI.

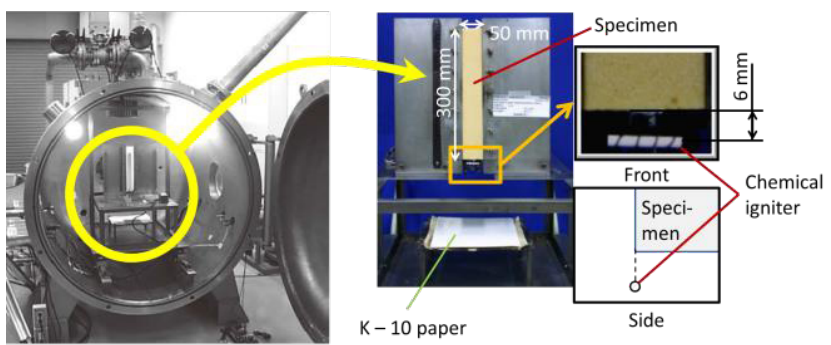

Fig. 1. A testing facility of TEST1/ISO-TS16697. Left: overview, right: magnified image of chemical igniter. ${ }^{6}$

One must notice that the chemical igniter shall burn with non-premixed (diffusion) combustion mode so that the heat release generated must be strongly affected by the environmental conditions ${ }^{3,7)}$, especially for the ambient oxygen concentration. Let us see typical examples in Fig. 2; where exhibits the time-sequential flame images brought by the chemical igniter under low and normal oxygen concentrations (16 and 20.9 vol. \%, respectively). Chemical igniter is heated by the wire heater to induce the forced 
ignition and subsequent combustion. Obviously the appearance of flame (e.g., luminous intensity, flame height) is quite different so that the heating performance brought by this igniter would vary accordingly.

(a) Oxygen concentration : 16 vol.\%

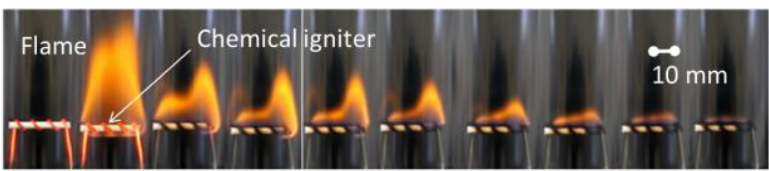

(b) Oxygen concentration : 20.9 vol.\%

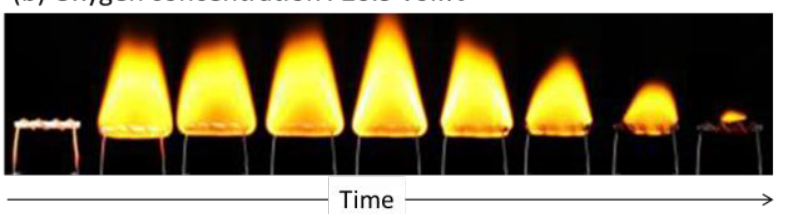

Fig. 2. Appearance of flame formed over the chemical igniter under various oxygen environments (a) 16 vol. $\%$ and (b) 20.9 vol. $\%$.

Suppose that heating performance brought by the chemical igniter becomes less under very low oxygen concentration condition (near-limiting condition), it may fail to ignite the specimen due to insufficient heat delivered. Since ISO-TS16697 is designed to examine the "extinction (i.e., critical condition for prohibiting the self-burning)", not "ignitability" to classify the material flammability, the igniter must provide sufficient heat to achieve a successful ignition. On the contrary, excess heat input would cause another problem because the test configuration is based on "upward flame spread" mode. When the heat release from the igniter is too strong, during the ignition process, a large amount of heat shall be transferred to the downstream of the specimen and the specimen store the equivalent enthalpy to promote the flame spread. With this regard, the heating performance brought by the igniter must be well-controlled and optimized, moreover, should be insensitive to the applied environmental condition.

The aim of this study is to understand the effect of the oxygen concentration on burning character, especially for heating performance, brought by the chemical igniter used in ISO-TS16697 as well as TEST1. The temporal heat flux brought by the flame formed over the chemical igniter is recorded by the heat flux gauge placed above it and ambient oxygen concentration is varied as the main experimental parameter. After the burning test, the weight of residue is measured to check the incompleteness of combustion. This work could extend in near future to propose the most preferred igniter to achieve successful ignition under various ambient conditions in order to give the acceptable flammability criteria of the material, which is useful for the screening purpose.

\section{Experiment}

\subsection{Experimental apparatus and conditions}

Figure 3 shows the illustration of experimental apparatus used in this study. Burning test was operated in the vertically-oriented chimney in which the prescribed oxidizer flow is adopted. A mixed gas of nitrogen and oxygen was fed from the bottom of the chimney (diameter: $142 \mathrm{~mm}$, length: $450 \mathrm{~mm}$ ) and exhausted to ambient at the top opening. At the bottom of the chimney, the \# 40 mesh was installed in order to remove eddies to allow the flow uniform. Its mixture composition and flowrate were controlled by mass flow controller (Kofloc GFC 200) whose accuracy is $\pm 1.0 \%$ F.S. Total volume flow rate was set to $11.9 \mathrm{ml} / \mathrm{min}$ (corresponding exit velocity is $12.8 \mathrm{~mm} / \mathrm{s}$ ) throughout the study. Oxygen concentration considered in this work was varied from 16 vol. $\%$ to 30 vol. $\%$, denoted as $\mathrm{O}_{2}$ atm hereafter.

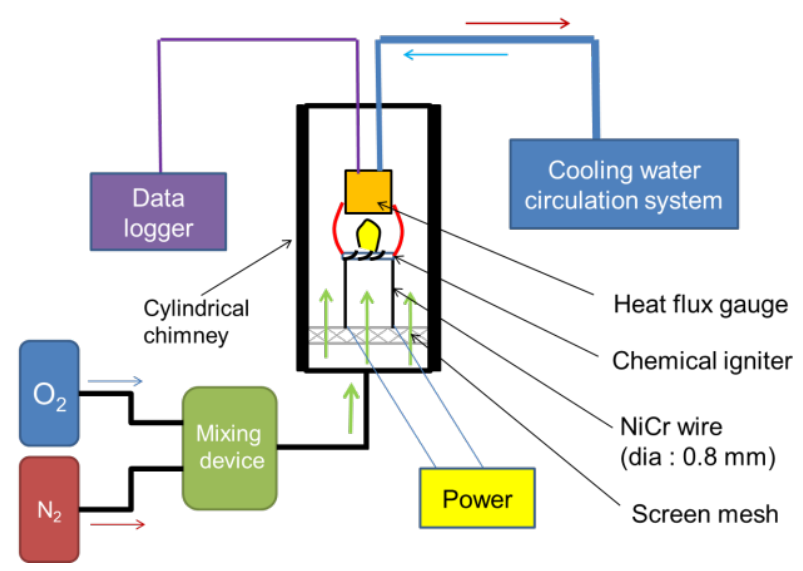

Fig. 3. Schematic illustration of experimental apparatus.

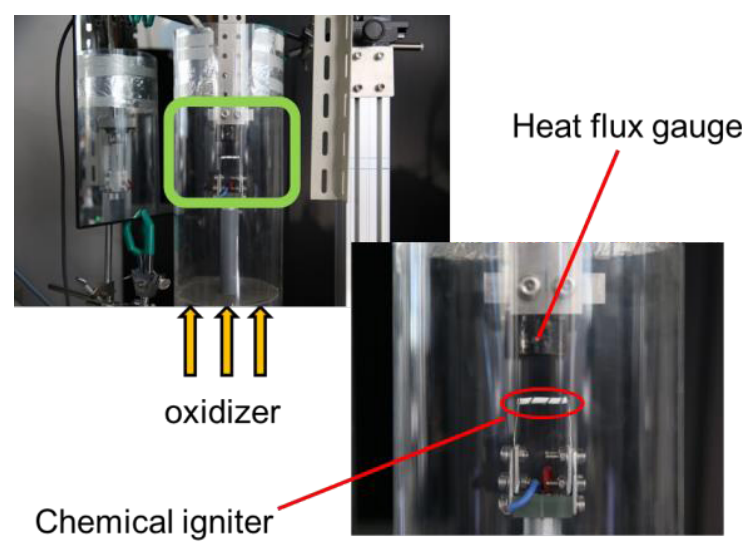

Fig. 4. Magnified image of chemical igniter.

The chemical igniter was placed in the chimney with holder and the flux gauge (CAPTHERM) was set above the igniter (6 $\mathrm{mm}$ and $25 \mathrm{~mm}$; denoted as $\mathrm{H}$ hereafter). By the way, the specimen should be set at $6.0 \mathrm{~mm}$ above the chemical igniter regulated by ISO-TS16697 to obtain ULOI. ${ }^{3)}$ Figure 4 shows the magnified image of the chemical igniter. It was placed in coil heater made by Nickel-chrome (NiCr) wire and initiated by applying the constant current of $15 \mathrm{Amp}$ to the coil to heat it up sufficiently. Table 1 summarizes ingredients and the standard specification (these items must be passed to be used in TEST1/ISO-TS16697) in detail. ${ }^{8,9)}$ 
Table 1. Specifications of the chemical igniter. ${ }^{8,9)}$

\begin{tabular}{|l|l|}
\hline Items & Specification \\
\hline \hline Ingredients & $\begin{array}{l}\text { Hexa-methylene-tetramine: } 70.2 \% \\
\text { Sodium metasilicate: } 26.3 \% \\
\text { Gum Arabic: } 3.5 \% \\
\text { (accuracy: } \pm 0.1 \%)\end{array}$ \\
\hline Weight range & $190 \mathrm{mg} \sim 240 \mathrm{mg}$ \\
\hline Flame temperature & $1100 \pm 90$ degree C \\
\hline Burning time & $25 \pm 5 \mathrm{sec}$ \\
\hline Flame height & $65 \pm 6.5 \mathrm{~mm}$ \\
\hline Heat amount & $3000 \mathrm{~J}$ \\
\hline
\end{tabular}

Whole burning event was recorded by the digital video camera (Canon EOS 5D Mark III; shooting conditions are; 500 of ISO sensitivity, shutter speed $1 / 30 \mathrm{~s}$, and an aperture of 32 (f32)) to capture the time sequence of flame appearance. The heat flux measured by the heat flux gauge was recorded by the data logger (Graphtec GL-900-8) with sampling rate of $10 \mathrm{~Hz}$. In order to measure the residue, before/after the test, weight of the chemical igniter was carefully measured by the digital balance (Mettler Toledo AT201).

\subsection{Error estimation}

Error analysis was made prior to the productive run to determine the effective number of experiments to hold the accuracy within $95 \%$ and $\pm 10 \%$ of confidence. To do this, sufficient runs are performed under the identical condition to analyze its dispersion. Based on Student-t distribution concept, the number of the test necessary to fulfill the requirement should be given in the following formula:

$$
n \geq\left(\frac{Z_{\text {infinity }}}{0.1 \times \mu}\right)^{2} \sigma^{2}
$$

where $n$ is the number of the test required, $Z_{\text {infinity }}$ is ideal $t$-number obtained with an infinite number of the test, $\mu$ is the mean value and $\sigma$ is the standard deviation, respectively.
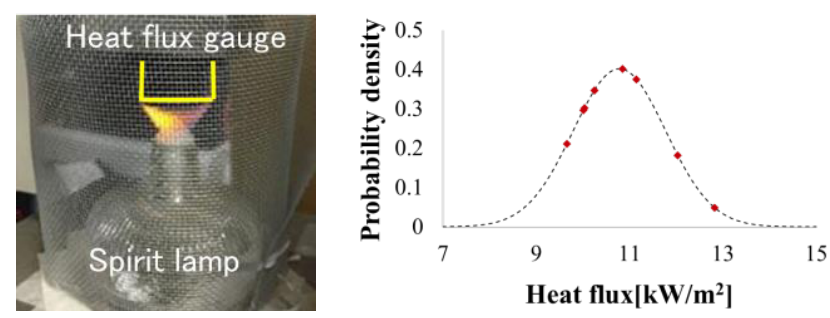

Fig. 5. Preliminary test to check the reproducibility in the present system.

We have performed the preliminary test of measuring heat flux over the reference flame (spirit lamp). Test device and typical result are shown in Fig. 5. Measurement have been attempted 10 times to obtain the mean value, $\mu$, and standard deviation (i.e. variance), $\sigma$, from the data analysis. Assuming that 10 -times test is satisfactory to impose an ideal $t$-number. From the probability curve as shown in Fig. 5 and confidence coefficient is set to 0.95 ( $95 \%$ of confidence), a typical test number to satisfy the imposed reproducibility is calculated as follows.

$$
n \geq\left(\frac{Z_{\text {infinity }}}{0.1 \times \mu}\right)^{2} \sigma^{2}=\left(\frac{1.96}{0.1 \times 10.78}\right)^{2} \times 0.9921^{2}=3.25
$$

Hence, 4 times runs are (at least) necessary to evaluate data in satisfactory level when the flame is steadily exposed onto the flux gauge. Of course the number should be increased when the flame would be fluctuated and the data of heat flux would vary largely (i.e. standard deviation becomes large). Although we will show in later, the flame formed over the chemical igniter is very steady when the imposed oxygen concentration is high enough ( $>18$ vol.\%), however, the stability becomes less under lower oxygen concentration $(<17$ vol.\%). Considering altogether, in this study, the number of productive test run is generally set to 4 times. If necessary, it is set to double ( 8 times) in case when the fluctuation is expected.

\section{Results}

\subsection{Overall flaming behavior}

Figure 6 shows the typical flames formed over the chemical igniter under various oxygen concentrations $\left(\mathrm{O}_{2}\right.$ atm $)$ with two kinds of the spacing between the igniter and the heat flux gauge (namely, $\mathrm{H}=6 \mathrm{~mm}$ and $25 \mathrm{~mm}$, respectively). Because the heat flux gauge acts as anstacle against the buoyancy-driven flow, the flow field becomes similar to the stagnation point flow. Accordingly, overall flame shape shows different from that of free burning (see Fig. 2). It is clearly found that the features of flame (e.g., flame color and luminous intensity etc) vary depending on the atmospheric oxygen concentration. It is worthwhile to note that the flame size also varies depending on the atmospheric oxygen concentration, suggesting that the mass flux from the igniter varies against the imposed conditions.

(a)

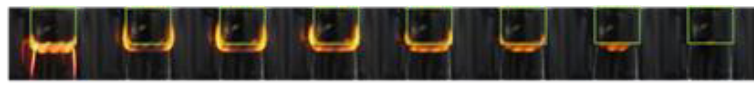

(b)

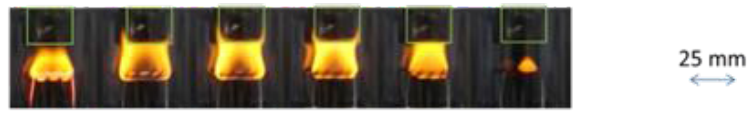

(c)

(d)

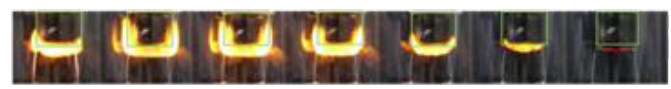

d)

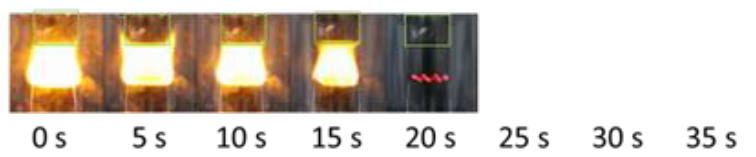

Fig. 6. Time-sequence of flame images during the burning event of the chemical igniter. (a) $\mathrm{O}_{2}$ atm $=20.9$ vol. $\%, \mathrm{H}=6 \mathrm{~mm}$; (b) $\mathrm{O}_{2 \_}$atm $=20.9$ vol. $\%, \mathrm{H}=25 \mathrm{~mm}$; (c) $\mathrm{O}_{2 \_}$atm $=30$ vol. $\%, \mathrm{H}=6 \mathrm{~mm}$; (d) $\mathrm{O}_{2 \_}$atm $=30$ vol. $\%, \mathrm{H}=25 \mathrm{~mm}$.

\subsection{Burning time}

Figure 7 shows the burning time measured by the visual 
image under the condition studied. As shown in this figure, two distinctive trends are found depending the atmospheric oxygen concentration. When the oxygen concentration is larger than that critical value (>18 vol.\%) the burning duration becomes nearly the constant with the change of the atmospheric oxygen concentration irrespective at two different height $(\mathrm{H}=6 \mathrm{~mm}$ and $25 \mathrm{~mm})$ is considered. On the contrary, strong dependency on ambient oxygen concentration is found less than the critical value ( $<18$ vol.\%), interestingly, opposite trend depending on the measuring position is identified. This suggests that the presence of heat flux gauge placed above the igniter does strongly affect the burning event of the igniter, especially under lower oxygen concentration. Since burning duration becomes shorter when the heat flux gauge is closer $(\mathrm{H}=6 \mathrm{~mm})$, it would act as heat sink to prohibit the continuous burning. The reason to achieve longer burning in lower atmospheric oxygen concentration at $\mathrm{H}=25 \mathrm{~mm}$ might be due to the irregularity of the flame, as noted in Fig. 6. One edge would extra-ordinary elongated when the heat flux gauge is placed relatively away from the igniter $(\mathrm{H}=25 \mathrm{~mm})$. Such elongation never been shown when heat flux gauge was set to closer to the igniter $(\mathrm{H}=6 \mathrm{~mm})$. In this sense, elongation of burning time under lower oxygen concentration with $\mathrm{H}=25$ $\mathrm{mm}$ is not physically meaningful.

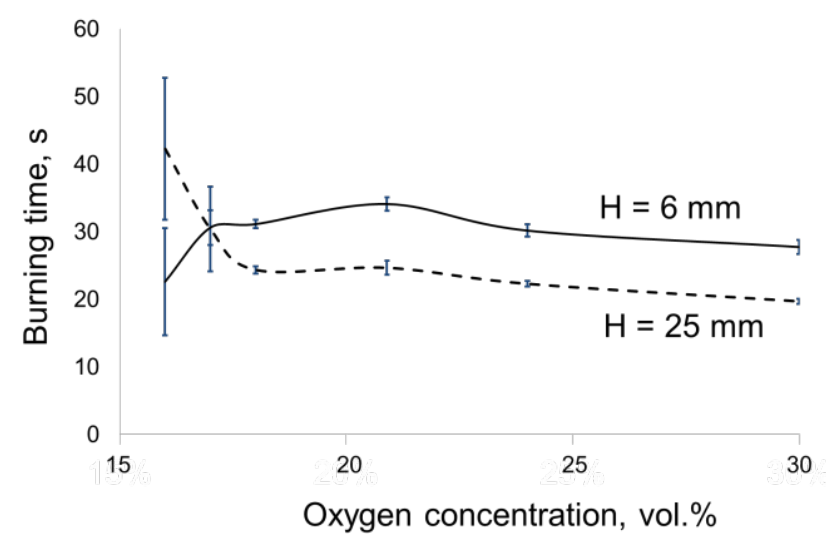

Fig. 7. Effect of atmospheric oxygen concentration on burning duration (time) of the chemical igniter.

\subsection{Incompleteness of combustion of the chemical igniter under low oxygen concentration}

Figure 8 shows result in weight loss ratio, namely, how much of percentage the weight of the chemical igniter is lost by combustion at each condition. In the figure, "theoretical" line estimated by the composition of the igniter (see Table 1) is embedded in order to show the theoretical burnout criterion. From this figure, again, two distinctive features are shown. At more than 18 vol. $\%$ of $\mathrm{O}_{2}$ atm, the chemical igniter well burns to reach fairly close to the theoretical value. At less than 17 vol. $\%$ of $\mathrm{O}_{2}$ atm, on the other hand, incomplete combustion of the chemical igniter is experienced. This result suggests that the heating performance brought by the chemical igniter shall be weaken under lower atmospheric oxygen concentration condition $\left(<18\right.$ vol. $\%$ of $\mathrm{O}_{2}$ atm) . We will discuss this issue in later.

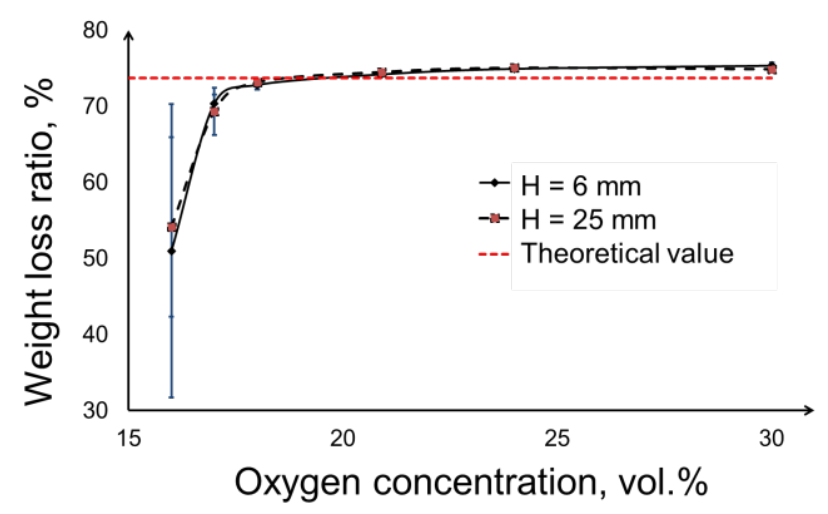

Fig. 8. Effect of atmospheric oxygen concentration on weight loss ratio of the chemical igniter.

Above-mentioned incomplete combustion of the chemical igniter can be clearly notified by comparing the direct picture of the igniter after the burning as shown in Fig. 9. In this figure, typical outlook of the chemical igniter before/after the burning event under 16 vol. $\%$ of $\mathrm{O}_{2}$ atm is shown. It is recognized that, in several the chemical igniter after burning, there is clear "spiral" black mark, indicating that the gentle burning at the potion attached to the nickel-chrome wire (to initiate the ignition) was only proceeded and no flaming surrounded over the igniter was made. Interestingly, some of the chemical igniter burns only certain portion and the other part was left over without burning. In such case, the flame formed over the chemical igniter would become an irregular (non-symmetric) shape. This matches to the observation fact as stated in Sec. 3.1 so as to Fig. 2. It should be important to note that the irregularity was randomly appeared suggesting that irregularity would be uncontrollable error by using the combination of wire coil and the igniter.

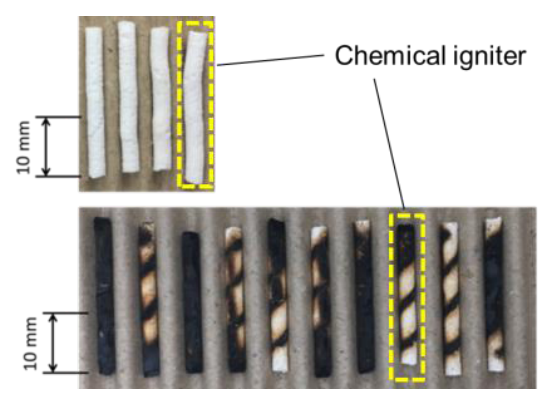

Fig. 9. Examples of outlook of the chemical igniter before(top)/after(bottom) of the burning event.

\subsection{Heat flux measurement}

Figure 10 shows the temporal heat flux measured by the heat flux gauge in various oxygen concentrations $\left(\mathrm{O}_{2}\right.$ atm $=$ $16,20.9$ and 30 vol.\%) at two different locations $(\mathrm{H}=6 \mathrm{~mm}$ and $25 \mathrm{~mm})$. In the figure, temporal flame images are embedded and the shooting time is indicated as circle in the curves. It is important to notice that the heat flux history shows several peaks in general during the burning event. Most likely two peak structure is generally found; namely, first peak appeared after the ignition and then gentle negative peak is taken for a long term, then eventually the second (positive) 
peak appeared just before the dying the flame. Although the temporal change of heat flux is not so apparent, averaged heat flux does change according to the imposed ambient oxygen concentration (see Fig. 11). Assuming that the chemical igniter is completely burned, total heat generated by the igniter must be identical. Namely, the integrated value of the heat flux by time must be constant. Such trend is qualitatively held when the cases (a) and (b) for $\mathrm{H}=6 \mathrm{~mm}$ are compared. However, the same scenario cannot be applicable to the case (c), obviously the (averaged) heat flux becomes lower but the time burn becomes less so that the total heat received must be less. This fact suggests that the complete combustion of the chemical igniter cannot be experienced in case (c), at which the imposed ambient oxygen concentration is lower (16 vol.\%; close to the extinction limit). This is consistent to what are observed in the previous section (Sec. 3.3), ensuring that the insufficient heat is delivered by the chemical igniter when the ambient oxygen concentration is less than critical value $(<18$ vol. \%).
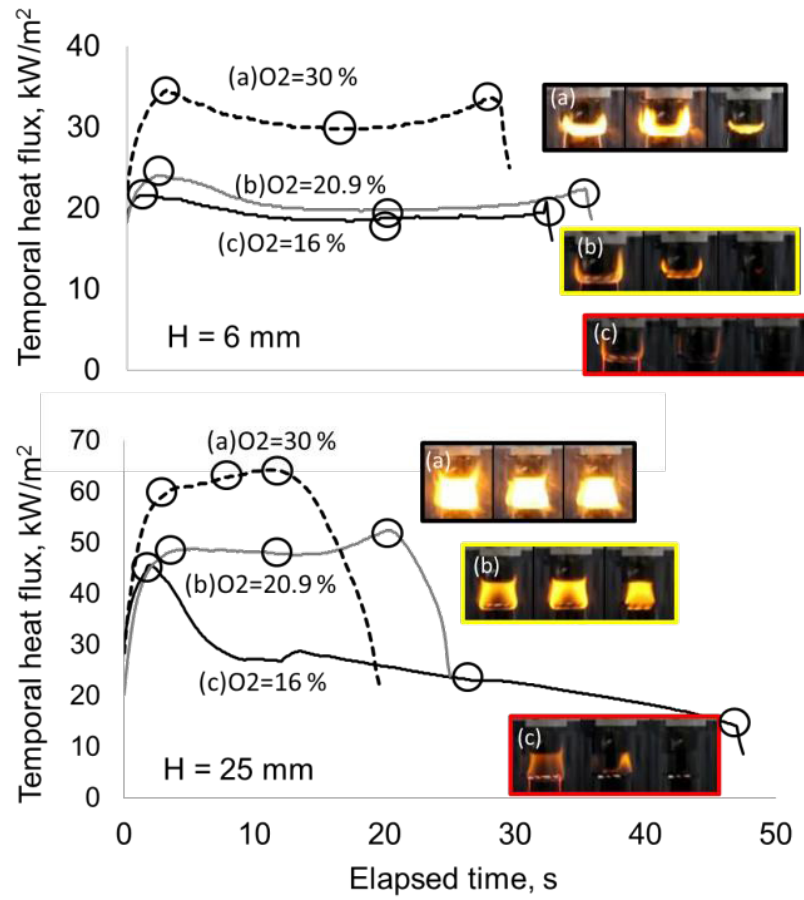

Fig. 10. Temporal change of heat flux under various oxygen concentrations ((a) 30, (b) 20.9, and (c) 16 vol.\%, respectively) at two different locations $(\mathrm{H}=6 \mathrm{~mm}$ and $25 \mathrm{~mm})$. Temporal flame images are embedded in the figure. Circles indicate the time where the corresponding temporal flame image is taken.

Similar trend can be found at the higher location $(\mathrm{H}=25$ $\mathrm{mm}$ ), one notable issue is found in lower oxygen concentration $\left(\mathrm{O}_{2}\right.$ atm $=16$ vol.\%). In this case, the first positive peak is clearly shown, however, the heat flux drops extensively after the appearance of the first peak, then gentle decrease is kept continue to achieve "slow-and-longer" heating. This is caused by the inhomogeneous combustion (flaming) induced by the chemical igniter as shown in the embedded images. As summarized in Fig. 11, therefore, the averaged heat flux is heavily affected by the imposed ambient oxygen concentration and the error is extra-ordinary promoted for $\mathrm{H}=25 \mathrm{~mm}$. Overall, imposing $\mathrm{H}=6 \mathrm{~mm}$ is better configuration to minimize the fluctuation of the heat flux brought by the chemical igniter. Nevertheless, it must be emphasized that the averaged heat flux is not constant against the imposed ambient condition. In other words, the heating performance brought by the chemical igniter does vary with the change in ambient condition.

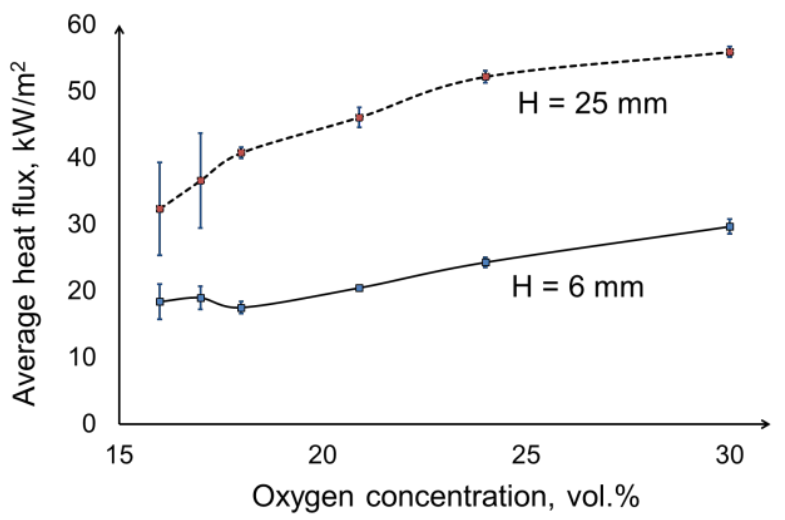

Fig. 11. Effect of atmospheric oxygen concentration on averaged heat flux.

Case 1

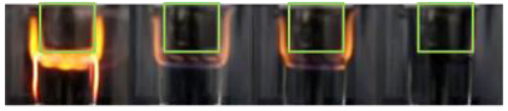

(a)

Case 2

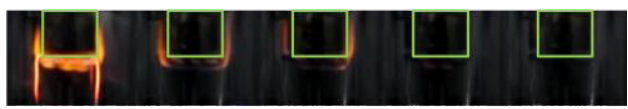

Case 3
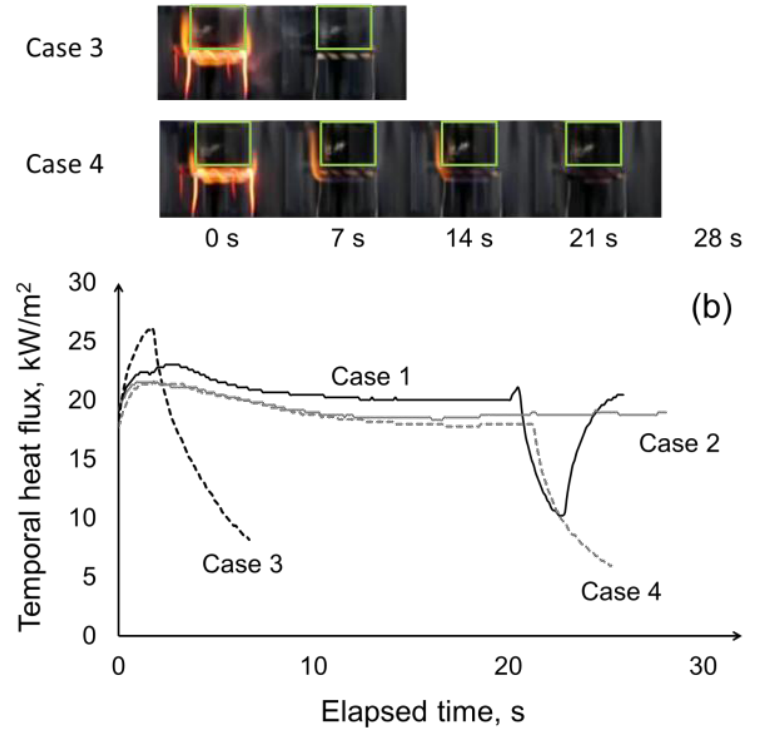

Fig. 12. Temporal change of flame appearance (a) and heat flux (b) for $\mathrm{H}=6 \mathrm{~mm}, \mathrm{O}_{2} \_$atm $=16$ vol. $\%$..

Also even at $\mathrm{H}=6 \mathrm{~mm}$, the error is pronounced (i.e. not negligible) when lower oxygen concentration is imposed. Large uncertainty should be caused by inconsistent flaming feature during the burning event. Selected four cases of temporal change of the flame images and heat flux are shown in Fig. 12. Obviously random behavior is found and the 
difference in flame appearance causes the difference in heat flux accordingly. It seems that the nearly identical heat flux can be delivered as long as the igniter burns well, however, it is unexpected that when such stable burning is temporally cease or recover. Such unstable behavior is not controllable even though the chemical igniter is carefully made uniformly. Thus the uncertainty found in lower oxygen concentration is not controllable and should be recognized as the system error, which is unavoidable one as long as the chemical igniter is used as the heating source.

\section{Discussion}

\subsection{Potential problems of chemical igniter as the heat source of the screening test}

Through the observations so far, it is confirmed that at least two features are pointed out when the chemical igniter is used as heat source; such as (1) heat flux brought by it can be varied according to the imposed ambient condition, (2) stability (reproducibility) of providing heat becomes less when the lower oxygen concentration is imposed. These features could become the potential problems when the chemical igniter is used for the screening purpose. Here are example cases.

As is well-known, TEST1 is operated under the fixed condition (the same as cabin in ISS) with "actual-size" of specimen for the screening test. Consider that the specimen is very flammable (it could burn under lower oxygen concentration) but is very thicker. Since large amount of heat must be transferred to ignite thicker specimen, it might fail to ignite it even though it is very flammable in reality. Then the screening test shall be "passed", even it is expected to burn if longer heating is employed. In this sense such kind of risk cannot be screened when the chemical igniter is used as standard ignition device (heat source).

On the contrary, following ISO-TS16697 protocol to find ULOI, it could not provide sufficient heat flux to ignite the specimen if the real flammability of the specimen is pretty low. For instance, the chemical igniter cannot test and obtain the value of ULOI if the critical oxygen concentration to burn the specimen is 10 vol.\% because the chemical igniter cannot burn well under such low oxygen concentration atmosphere. In addition, quality of the screening test might not be good due to the less reproducibility is pronounced when the lower oxygen concentration is imposed, say 16 vol.\% of $\mathrm{O}_{2}$ atm. With this regard, ULOI around such value might not be reliable. Although it is true that such highly-flammable material is not basically considered for space-use and above-mentioned problem is naturally avoidable, this does not mean that the chemical igniter is the best selection for reference ignition source.

\subsection{Preferred heating character as standard ignition source}

Before discuss about the alternative of the chemical igniter, it is necessary to examine about what kind of character would be the preferred heating performance for heat source of material flammability screening test. Naturally above- mentioned two features must be overcome, however, this is actually not enough and one additional issue must be considered; such as the controllability of the heating rate (i.e., value of the exposed heat flux for heating).

To explain the reason in detail, let us consider what will be direct cause to achieve successful ignition of the specimen; this is minimum requirement the igniter should achieve, as shown in Fig. 13. To reach the successful ignition of the specimen, the specimen must be heated up to evolve the combustible gas from it. In general, gasification can be achieved when the maximum temperature of the specimen must beyond certain temperature, what we call "gasification temperature: $\mathrm{T}_{\mathrm{g}}$ ". Namely, from physical process point of view, the heat flux exposed onto the specimen brought by the igniter must be enough to reach the temperature of the specimen over $\mathrm{T}_{\mathrm{g}}$.

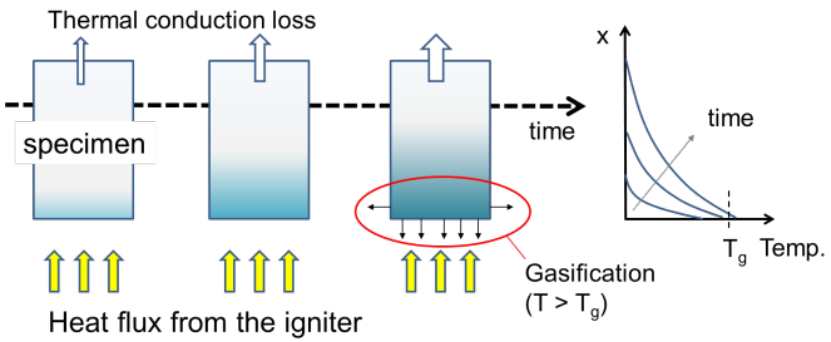

Fig. 13. Schematic illustration of ignition process of the specimen exposed by the heat flux from the bottom. Right figure shows the time-variation of temperature distribution inside the specimen $\left(\mathrm{T}_{\mathrm{g}}\right.$ : gasification temperature).

Let us consider the heat balance of the specimen exposed the heat flux to see whether its temperature could be above $T_{g}$. Since the exposed specimen is not thermally insulated, transferred heat from the bottom by the igniter can penetrate into the specimen and be lost from the heated zone via conduction inside the specimen. The speed (rate) of the conduction is generally slow, similar to the surface regression rate. Assume that the surface regression rate is $0.01 \times 10^{-3} \mathrm{~m} / \mathrm{s}$, the density of the specimen is $1 \times 10^{3} \mathrm{~kg} / \mathrm{m}^{3}$, the heat capacity is $1 \times 10^{3} \mathrm{~J} /(\mathrm{kg} \mathrm{K})$, and gasification temperature is $800 \mathrm{~K}$, then conduction heat flux can be estimated as $5 \mathrm{~kW} / \mathrm{m}^{2}$. Importantly, this is similar order to the heat flux brought by the chemical igniter as shown in Fig. 11.

To end, when the exposed heat flux is low onto the test specimen, most of the heat exposed could be lost and less amount of heat is effectively accumulated in the specimen to increase its internal energy. In this case, the time needed to reach $\mathrm{T}_{\mathrm{g}}$ becomes longer. Unfortunately, the burning time of the chemical igniter is limited, slower heating rate, i.e., low heat flux exposure could be improper condition to achieve the successful ignition of the specimen. With this regard, rate of heating (combined with the duration of the effective heating) is another important specification for the alternative igniter to be considered.

\subsection{Alternative candidate: electric wire ignition}

So far several disadvantages to use the chemical igniter for 
flammability screening test are identified and discussed. Eventually, let us propose an alternative igniter device which could cover disadvantages mentioned; namely, electric wire-heating method.

Heating performance provided by the electric heater made by the $\mathrm{NiCr}$ wire with folded pattern was tested as shown in Fig. 14. $440 \mathrm{~mm}$ full length of $\mathrm{Ni}-\mathrm{Cr}$ wire was used as heat source and the power supply was used to impose the prescribed current to the wire. The folded pattern was arbitrary designed in order to supply the heat effectively toward the specimen to be heated (ignited). Heat flux gauge was placed $3 \mathrm{~mm}$ over the $\mathrm{NiCr}$ wire to measure the heat flux.
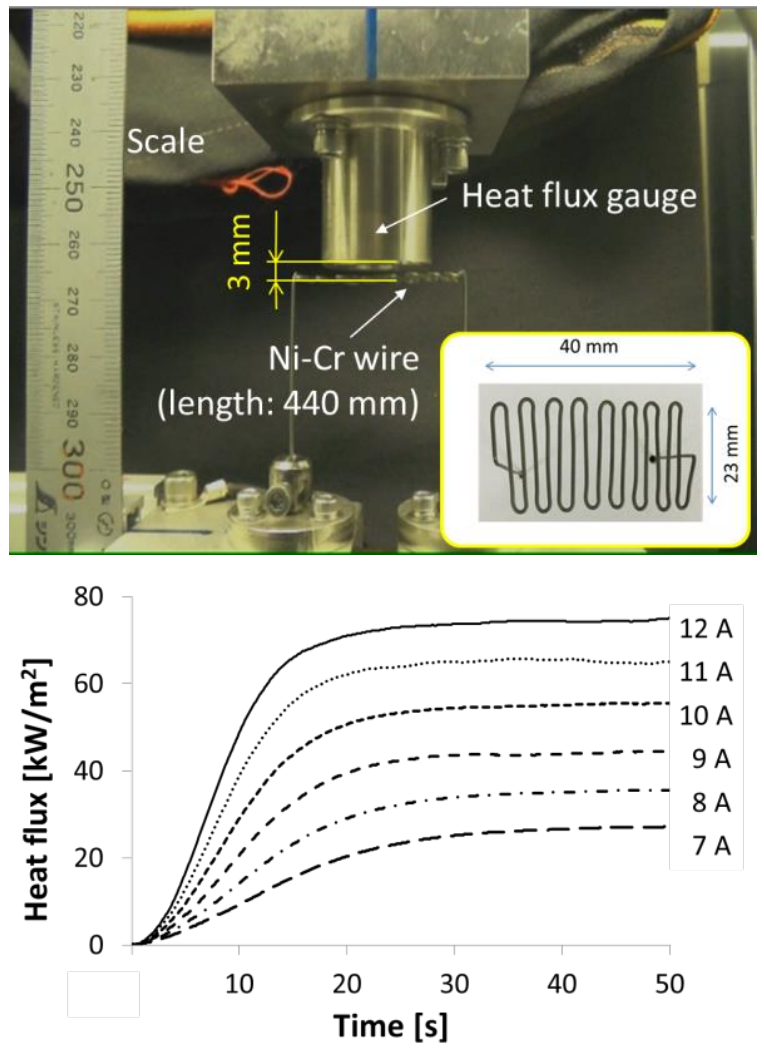

Fig. 14. Heat flux measurement induced by the folded-pattern NiCr wire with various applied current via power supply.

As shown in this figure, although there is a certain delay time, very constant, controllable steady heat flux can be provided for all condition studied here. By adopting $\mathrm{NiCr}$ wire as an alternative igniter of vertically-oriented specimen, successful ignition was achieved as shown in Fig. 15. $\mathrm{NiCr}$ wire was placed under $3 \mathrm{~mm}$ beneath of the specimen. The test was made under the standard air environment (namely, 21 vol. $\% \mathrm{O}_{2} \_$atm) and no ignition was achieved under 9 amp of the applied current. Ignition delay time decreases (exponentially) as the applied current increases; asymptotically approach to infinite delay time at $9 \mathrm{amp}$. Again, according to Fig. 14, even at $9 \mathrm{amp}, \mathrm{NiCr}$ wire can provide very steady heat flux so that reproducibility must be very high.

No flaming is notified for $\mathrm{NiCr}$ wire heating method because no flammable gas was evolved from the igniter (not likely as the chemical igniter). Thus, heating performance must be consistent by any ambient oxygen concentration imposed. One thing must be wondered is aging due to forming the oxide layer over the wire, accordingly, the resistance should be varied. We have tested the aging effect under open air environment with $11 \mathrm{amp}$, confirming that only less than $3 \%$ increase of resistance over 20 times runs. When the resistance varies, controlling the applied current could compensate to generate the same amount of Joule heat, which could sustain the consistent heating performance as igniter.
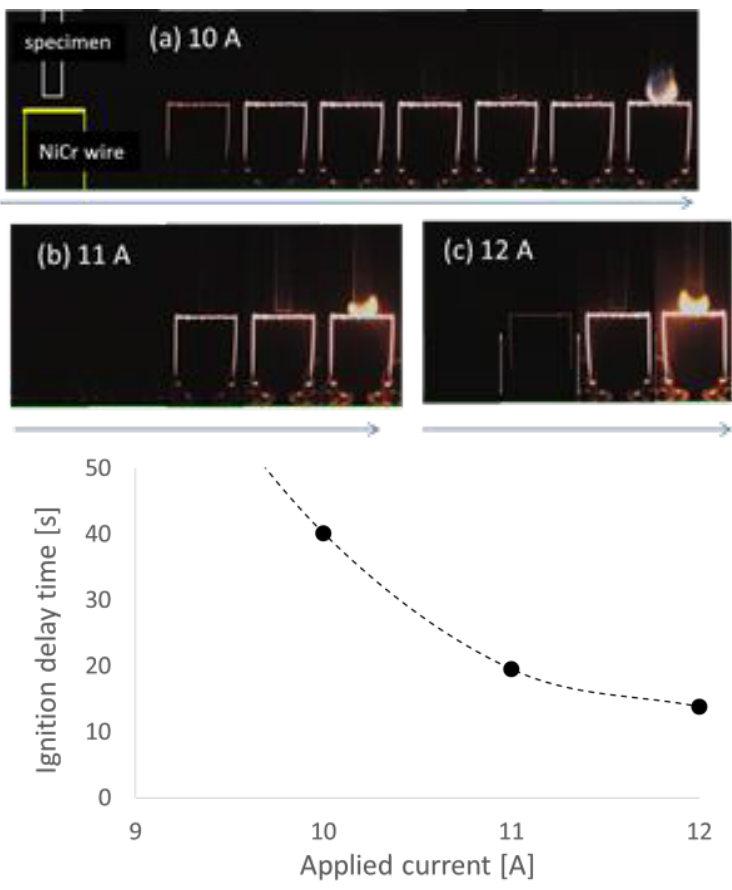

Fig. 15. Ignition of 4mm-thich PMMA specimen under standard atmospheric condition by $\mathrm{NiCr}$ wire applied with various currents.

Overall, introducing the electric wire would be one of potential and practical choices against the chemical igniter. It is worthwhile to note that NASA has attempted that the electric heater was employed to obtain ULOI quite recently. ${ }^{10)}$ Although they did not say officially the possibility about the wire ignition to be substitute of the chemical igniter, through the present study, it has been revealed that such attempt is worthwhile to consider.

\section{Conclusion}

In this study, quantitative evaluation on the heating performance of the chemical igniter is investigated under various atmospheric oxygen concentrations experimentally. It turned out that the heating performance brought by the chemical igniter has strong dependency on atmospheric oxygen concentration condition. Uncertainty is pronounced when the atmospheric oxygen concentration becomes less than 18 vol.\% so that the chemical igniter system might not be appropriate to find the exact flammability limit of the material, whose limiting oxygen index is less than 18. Lower heating rate with limited heating duration is not enough to achieve the 
ignition of the specimen so that the igniter must fulfill this requirement as well. To be more concrete, an alternative igniter system should be developed in order to avoid those disadvantages provided by the chemical igniter. As one of candidate, we have examined the heating performance via an electric wire ignition method and found that it could be potential as well as practical choice to overcome difficulties brought by the chemical igniter. We will continuously study on the feasibility by adopting the electric wire ignition system to measure the material flammability in space.

\section{Acknowledgments}

This work has been proceeded as part of the project named "FLARE" registered as the 3rd phase utilization of JEM/ISS in JAXA. Technical guidance/assistance brought by Research and Development Division at JAXA was helpful to conduct this work.

\section{References}

1) NASA-STD-6001 B, Flammability, Offgassing, And Compatibility Requirements And Test Procedures, NASA, 2011.

2) Campbell, P. D.: Recommendations For Exploration Spacecraft Internal Atmospheres: The Final Report Of The NASA, NASA JSC-63309 Exploration Atmospheres Working Group, 2006.

3) Pedley, M. D.: Flammability Configuration Analysis For Spacecraft Applications, JSC 29353, NASA Johnson Space Center, Houston, Texas, 2002.

4) ISO/TS 16697, Space Systems -- Safety And Compatibility Of Materials -Method To Determine The Flammability Thresholds Of Materials, 2012.

5) Dixon, W.: Up-and-Down Method For Small Samples, American Statistical Association Journal, 60 (1965), pp. 967-970.

6) Hosogai, A., Nakamura,Y., Wakatsuki, K., Kimoto, Y.: Comparison Between The Limiting Oxygen Index And Upward Flame Propagation Test (NASA-STD-6001/Test 1), 29 International Symposium on Space Technology and Science, ISTS, Nagoya, June 2013.

7) Kuo, K. K.: Principles of Combustion, Wiley-Interscience (2004) ISBN: 978-0471046899, pp.537-622.

8) Manufacturing Of Igniters For NHB 8060.1 Testing, NASA White Sands Test Facility,1996.

9) Material Safety Data Sheet - NASA Standard 6001 Igniter, NASA Johnson Space Center, 2009

10) Personal communication with Dr. H. Beeson, NASA. 